\title{
Evaluation of New Composite Adsorbents for Solar-Driven Adsorption Refrigerator
}

\author{
Ahmed N. Shmroukh ${ }^{1 \square}$, Essam Hares ${ }^{2}$, Osama Hamdy $^{3}$, Mostafa Abouelsoud ${ }^{1}$
}

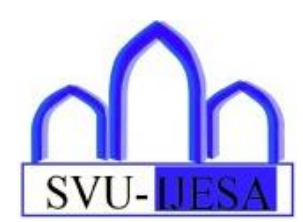

\begin{abstract}
Sustainability, nature conservation, and energy economy remain the significant points of the global community focus. Due to the rapid growth in the world wide consumption of limited conventional energy and the environmental consideration for refrigerant agents' choice, solar-driven adsorption refrigerators (SAR) have been the focal of extensive research for cooling and refrigeration applications subjected to meet the fast increase in refrigeration needs of the developing countries such as Egypt. A new two composite adsorbents consist of $95 \mathrm{wt} \%$ silica gel powder with $5 \mathrm{wt} \%$ activated carbon powder (SGC1) and 90wt\% silica gel powder with $10 \mathrm{wt} \%$ activated carbon powder (SGC2), used with water as a refrigerant agent in a solar adsorption refrigerator installed in Upper Egypt. These adsorbents were evaluated as eco-friendly and low-cost cooling storage for cooling fruits and vegetables within a convenient storage environment. The experiments were done under the weather conditions of Qena City in Upper Egypt. The main results showed that the best obtained coefficient of performance (COP) was about 0.174 for SGC1. The specific cooling power (SCP) value was about 0.0199 $\mathrm{kW} / \mathrm{kg}$ for SGC1. Moreover, the delivered evaporator temperature by the adsorption refrigerator can reach about $2.8-1.6^{\circ} \mathrm{C}$. These results revealed that the proposed new adsorbents are beneficial for storing vegetables and fruits in remote and rural areas where electrical power sources are insufficient or unavailable.
\end{abstract}

Keywords: Solar adsorption refrigerator; Silica gel; Eco-friendly; Storage

Received: 29 October 2021/ Accepted: 14 December 2021

$\square$ Ahmed N. Shmroukh, ahmed.shmroukh@eng.svu.edu.eg

1. Department of Mechanical Engineering, Faculty of Engineering, South Valley University, Qena 83521, Egypt

2. Department of Mechanical Power Engineering, Faculty of Energy Engineering, Aswan University, Aswan, Egypt

3. Department of Mechanical Engineering, Benha Faculty of Engineering, Benha University, Benha, Egypt

\begin{tabular}{|c|c|c|c|}
\hline$A_{b}$ & $\begin{array}{l}\text { adsorption bed total area } \\
\left(\mathrm{m}^{2}\right)\end{array}$ & $t_{c}$ & cycle time $(\mathrm{s})$ \\
\hline $\mathrm{C}_{\mathrm{p}, \mathrm{w}}$ & $\begin{array}{l}\text { water specific heat } \\
\mathrm{kJ} / \mathrm{kg} . \mathrm{K}\end{array}$ & $\mathrm{z}$ & measured value (-) \\
\hline I & $\begin{array}{l}\text { incident solar radiation } \\
\left(\mathrm{W} / \mathrm{m}^{2}\right)\end{array}$ & \multicolumn{2}{|c|}{ Greek symbol } \\
\hline$\dot{m}$ & $\begin{array}{l}\text { water mass flow rate } \\
(\mathrm{kg} / \mathrm{s})\end{array}$ & $\delta \mathrm{r}$ & results uncertainty \\
\hline $\mathrm{m}_{\mathrm{a}}$ & $\begin{array}{l}\text { composite adsorbent } \\
\text { quantity }(\mathrm{kg})\end{array}$ & \multicolumn{2}{|c|}{ Abbreviations } \\
\hline $\mathrm{N}$ & $\begin{array}{l}\text { number of measured } \\
\text { values }(-)\end{array}$ & $\mathrm{COP}$ & coefficient of performance \\
\hline $\mathrm{Q}_{\mathrm{e}}$ & power of cooling $(\mathrm{kJ})$ & SAR & $\begin{array}{l}\text { solar adsorption } \\
\text { refrigeration systems }\end{array}$ \\
\hline $\mathrm{Q}_{\mathrm{s}}$ & $\begin{array}{l}\text { input solar based heat } \\
(\mathrm{kJ})\end{array}$ & $\mathrm{SCP}$ & specific cooling power \\
\hline $\mathrm{T}_{\mathrm{h}}$ & hot temperature $\left({ }^{\circ} \mathrm{C}\right)$ & SGC & $\begin{array}{l}\text { silica gel powder with } \\
\text { activated carbon powder }\end{array}$ \\
\hline $\mathrm{T}_{\mathrm{R}}$ & $\begin{array}{l}\text { refrigeration temperature } \\
\left({ }^{\circ} \mathrm{C}\right)\end{array}$ & & \\
\hline
\end{tabular}

\section{Introduction}

In recent decades, environmentally friendly refrigeration systems received considerable attention due to global warming and Ozone layer depletion [1,2]. On the other hand, traditional refrigeration systems consume enormous amount of fossil fuels to be driven. Therefore, solar adsorption refrigeration systems (SAR) with efficient adsorbents and clean refrigerants as water can be treated as an intrinsic solution for such environmental problems [3]. Some features of SAR include but are not restricted to: simple design, being eco-friendly, no moving parts, suitable for portable applications, employing natural refrigerants, and low energy intensity and that way meeting the existing global regulations [4]. However, these systems are still under the aim of performance improvement [5].

Several researches were accomplished on using silica gel/water as adsorption pair in SAR. Chua et al. [6] investigated experimentally water adsorption characteristics onto two types of silica gels. Their results revealed that at $31{ }^{\circ} \mathrm{C}$ the maximum 
adsorption capacity of type RD silica gel reached about $0.45 \mathrm{~kg} / \mathrm{kg}_{\mathrm{ads}}$, and for type A silica gel reached about $0.39 \mathrm{~kg} / \mathrm{kg}_{\text {ads. }}$. Pan et al. [7] studied experimentally a developed silica gel/water based adsorption refrigerator considering heat and mass recovery. Their proposed system results showed that the cooling power, coefficient of performance (COP), and specific cooling power (SCP) were reached about $42.8 \mathrm{~kW}, 0.51$, and $125 \mathrm{~W} \mathrm{~kg} / \mathrm{kg}_{\text {ads }}$, respectively. Moreover, $\mathrm{Ng}$ et al. [8] analyzed experimentally the adsorption isotherms of three different types of silica gel. Their results demonstrated that at a regeneration temperature of $90{ }^{\circ} \mathrm{C}$ about $95 \%$ of the three silica gel types can be regenerated completely, and type $\mathrm{RD}$ gave the highest adsorption uptake at $30{ }^{\circ} \mathrm{C}$ of $0.36 \mathrm{~kg} / \mathrm{kg}_{\text {ads }}$. While, El-Sharkawy et al. [9] performed a theoretical study on solar adsorption refrigerators using silica gel/water adsorption pair, working under the weather conditions of Jeddah in Saudi Arabia, Aswan, and Cairo in Egypt. Their results demonstrated that the maximum cooling capacity of their proposed system reached about $15.8 \mathrm{~kW}$ for Aswan and $14.8 \mathrm{~kW}$ for both Cairo and Jeddah climate conditions. Furthermore, Zhu et al. [10] compared advanced four different types of adsorption beds with silica gel/water working pairs. The results demonstrated that the COP and SCP of the proposed beds can reach up to 0.30 and $198.4 \mathrm{~W} \mathrm{~kg} / \mathrm{kg}_{\text {ads }}$. Moreover, He et al. [11] proposed experimentally a compact adsorption refrigerator used for automobiles, with a volume of about $40 \mathrm{~L}$. They found that at $95{ }^{\circ} \mathrm{C}$ regeneration temperature the highest cooling capacity was $1.5 \mathrm{~kW}$. Vodianitskaia et al. [12] examined silica gel particle size effect on COP, SCP and net cooling power of adsorption refrigerator worked with silica gel/water adsorption pair. Their proposed system achieved high values of COP, SCP, and cooling power which reached up to $0.53,68 \mathrm{~W} / \mathrm{kg}$, and $143 \mathrm{~W}$ at regeneration temperature of $80{ }^{\circ} \mathrm{C}$. Furthermore, Liu et al. [13] studied experimentally a pure silica gel adsorbent with water refrigerant in a solar adsorption refrigerator. Their experimental test rig is built in Beijing City in China. Their proposed system results showed that COP and SCP were reached about 0.256 , and $8.13 \mathrm{~W} \mathrm{~kg} / \mathrm{kg}_{\mathrm{ads}}$, respectively.

From the mentioned point of view, it can be observed that using composite adsorption pairs in adsorption refrigerators still need essential development and research work to develop more efficient and compact adsorption refrigerators. The novelty of the present work is to use composite adsorbents consisting of silica gel powder and activated carbon powder with different weight percentages, for increasing water uptake, enhancing both heat and mass transfer in the solar adsorption bed, and improving both $\mathrm{COP}$ and $\mathrm{SCP}$ of the proposed solar refrigerator.

\section{Materials and Method}

The proposed SAR is illustrated in the following Figure.1, the prototype is constructed and tested in Qena Faculty of Engineering garden $\left(26^{\circ} 10^{\prime} \mathrm{N}\right.$ and $\left.32^{\circ} 43^{\prime} \mathrm{E}\right)$ $[14,15]$, this prototype helped in evaluating the operating parameters and feasibility of using such type of solar adsorption refrigerator in harsh climates for food reservation. The proposed solar adsorption refrigerator has the following components: a thermally insulated adsorption bed with $0.48 \mathrm{~m}^{2}$ effective area $(0.8 \mathrm{~m}$ length $\times$ $0.6 \mathrm{~m}$ width) equipped with 10 parallel red copper tubes spaced by $0.04 \mathrm{~m}$, an air-cooled condenser, an evaporator with $10 \mathrm{~L}$ effective volume, and refrigerant piping. During daytime the composite adsorbent contained in the solar-driven adsorption bed is heated by solar radiation, this promoted the refrigerant molecules (water) to be desorbed from the composite adsorbent (silica gel powder with activated carbon powder) and transformed into vapor. Then, the water vapor is condensed in the free convection air cooled condenser and directed towards the evaporator till the end of this desorption process. While, during nighttime the adsorbent is cooled gradually involving the refrigerant adsorption process to be started, producing the required cooling action in the evaporator.

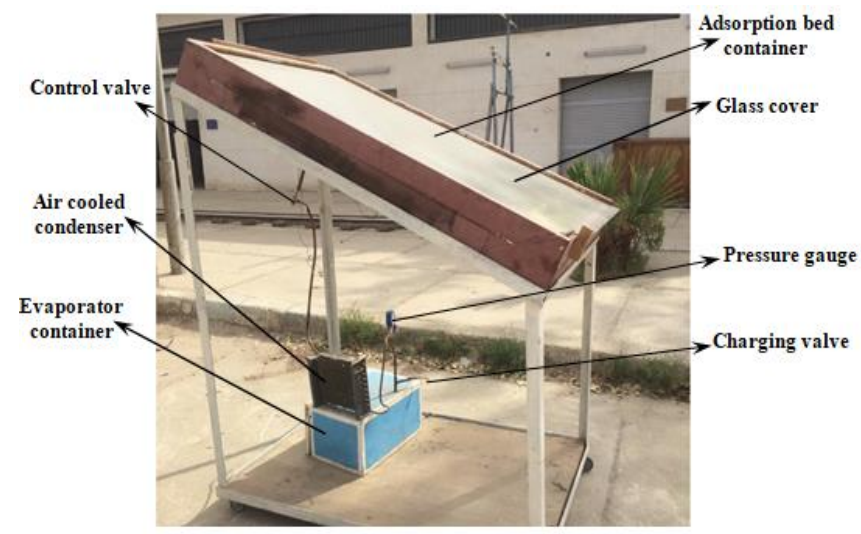

Fig.1 Proposed solar adsorption refrigerator.

The copper tubes of the adsorption bed have an internal diameter of $0.019 \mathrm{~m}$, they are backed with the proposed $3 \mathrm{~kg}$ of composite adsorbents before each experiment. Regarding the first experiment, the well 
mixed composite adsorbent consisted of $95 \mathrm{wt} \%$ silica gel powder and $5 \mathrm{wt} \%$ activated carbon powder, which can be named SGC1. While for the second experiment, the well mixed composite adsorbent consisted of $90 \mathrm{wt} \%$ silica gel powder with $10 \mathrm{wt} \%$ activated carbon powder, which can be named SGC2. Type-T thermocouples are attached in the required measuring points to accurately measure the adsorption bed, evaporator, condenser, and ambient temperatures, Figure 2 illustrates the piping and the final prototype of the adsorption bed container.

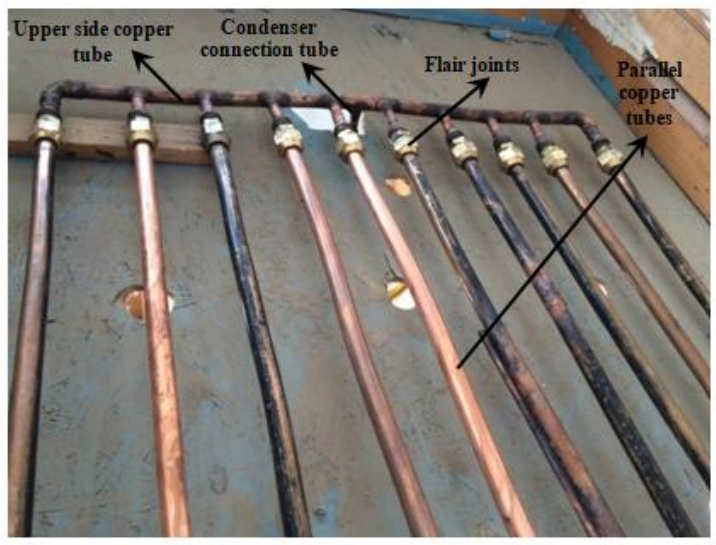

(a)

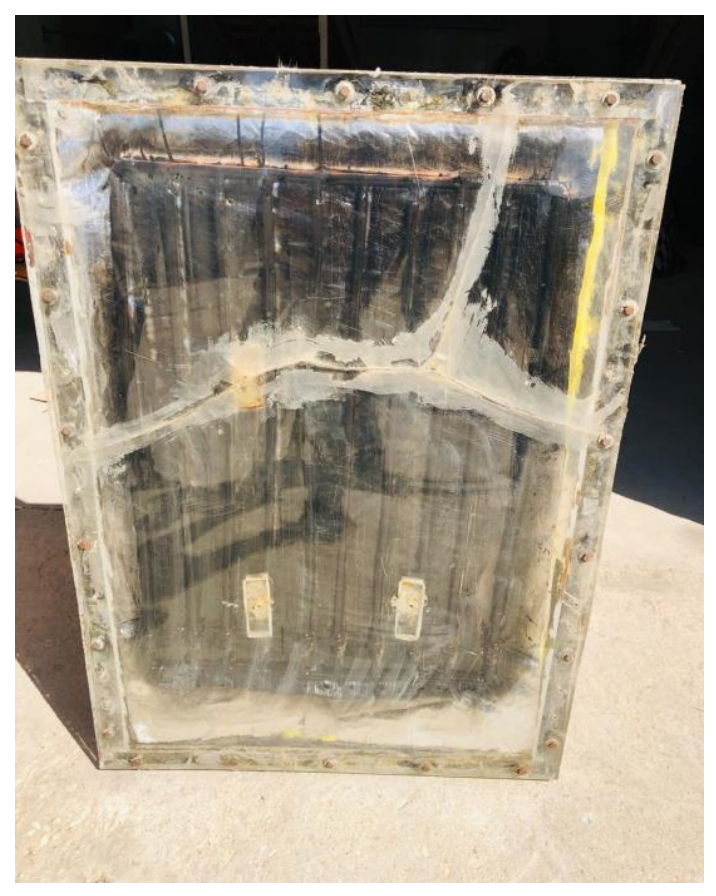

(b)

Fig.2 Adsorption bed assembly: a) copper tube connections, b) adsorption bed after packaging.

\section{Proposed system performances}

To evaluate the proposed SAR performance, essential parameters are required. One of the most essential parameters is the coefficient of performance (COP) of the solar adsorption refrigerator, which is the ratio of the average heat of cooling $\left(\mathrm{Q}_{\mathrm{e}}\right)$ produced by the system in $\mathrm{kJ}$ to the input solar based heat $\left(\mathrm{Q}_{\mathrm{s}}\right)$ to the system in $\mathrm{kJ}$ and it is calculated according to Eq. (1) [16].

$$
C O P=\frac{Q_{e}}{Q_{s}}
$$

Subsequently, to determine the average cooling power of the proposed solar adsorption refrigerator, Eq. (2) can be used [17].

$$
Q_{e}=\dot{m} C_{p, w}\left(T_{h}-T_{R}\right) t_{c}
$$

Where $\dot{m}, \mathrm{C}_{\mathrm{p}, \mathrm{w}}, \mathrm{T}_{\mathrm{h}}, \mathrm{T}_{\mathrm{R}}, \mathrm{t}_{\mathrm{c}}$, are water mass flow rate in $\mathrm{kg} / \mathrm{s}$, water specific heat $\mathrm{kJ} / \mathrm{kg} . \mathrm{K}$, the hot temperature in ${ }^{\circ} \mathrm{C}$, the refrigeration temperature in ${ }^{\circ} \mathrm{C}$, and the cycle time in $\mathrm{s}$, respectively. Moreover, the solar heat received by the adsorption bed can be is calculated by Eq. (3) [18].

$$
Q_{s}=\int I(t) A_{b} d t
$$

Where $I$ is the incident solar radiation in $\mathrm{W} / \mathrm{m}^{2}$, it is measured by using a sensitive digital pyranometer, and $A_{b}$ is the adsorption bed total area $\mathrm{m}^{2}$. On the other hand, the specific cooling power (SCP) in $\mathrm{W} / \mathrm{kg}_{\text {ads }}$ is one of the essential parameters for evaluating the performance of the proposed solar adsorption refrigerator, it can be determined by the relation (4) [19].

$$
S C P=\frac{\dot{m} C_{p, w}\left(T_{h}-T_{R}\right)}{m_{a}}
$$

Where $m_{a}$ is the composite adsorbent quantity in $\mathrm{kg}$, it is measured using a sensitive electronic scale. Regarding uncertainty and error analysis, the following procedure is used for calculating the uncertainty propagation [20,21], and Table 1 clarifies the obtained values from the calculations. 


$$
\delta r=\sqrt{\left(\frac{\partial r}{\partial z_{1}} \delta z_{1}\right)^{2}+\left(\frac{\partial r}{\partial z_{2}} \delta z_{2}\right)^{2}+\ldots .+\left(\frac{\partial r}{\partial z_{N}} \delta z_{N}\right)^{2}}
$$

Where $\delta \mathrm{r}$ is the uncertainty results, $\mathrm{z}$ is the measured value and $\mathrm{N}$ is the number of measured values [22]. Table 1 shows both measured and determined parameters uncertainty calculations' data.

Table 1. Error data for the determined and measured variables.

\begin{tabular}{|l|l|}
\hline Parameter & Error (\% of reading) \\
\hline Solar radiation intensity & Up to $\pm 1[14]$ \\
\hline Temperature & $\pm 0.1[18]$ \\
\hline COP & $\pm 1.1[1]$ \\
\hline SCP & \pm 0.9 \\
\hline
\end{tabular}

\section{Discussion of the experimental results}

Under the climatic condition of Qena City in the Upper Egypt zone, the proposed SAR is tested, during the period from 6:00 a.m to 6:00 p.m of almost two identical clear days on the 19th and 21st of September 2021.

The daily average variation of solar radiation intensity and adsorption bed, evaporator, condenser and ambient temperatures of SAR when using composite adsorbents SGC1 of $95 \mathrm{wt} \%$ silica gel powder and $5 \mathrm{wt} \%$ activated carbon powder, with water as a refrigerant on 19 Sep. 2021, is illustrated in Figure 3. The maximum solar radiation intensity of $1111 \mathrm{~W} / \mathrm{m}^{2}$ is available at noontime. Thereafter the amount of available solar radiation intensity decreases till the end of the test. The adsorption bed temperature reached its maximum value of $125^{\circ} \mathrm{C}$ at 1:00 p.m then it was reduced gradually, due to water desorption from the heated adsorption bed. While the evaporator temperature reached its lowest value of $2.1{ }^{\circ} \mathrm{C}$ at $3: 00 \mathrm{a} . \mathrm{m}$ due to water adsorption in the cooled adsorption bed. Regarding the ambient and condenser temperatures, both profile trends are nearly the same with condenser temperature values higher than that of ambient values, due to the extra heat in the desorbed water refrigerant in the condenser.

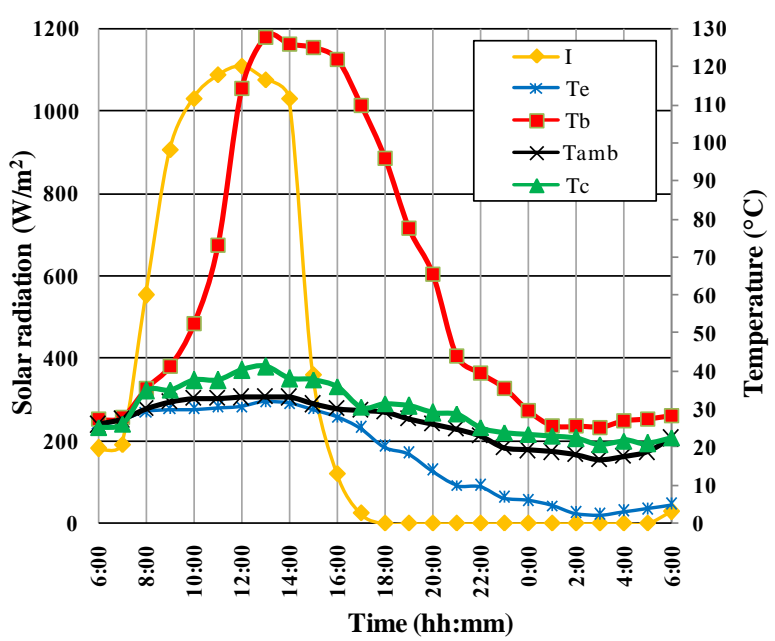

Fig.3 SAR with SGC1 temperature and solar intensity profiles on 19 Sep. 2021.

Moreover, the daily average variation of solar radiation intensity and adsorption bed, evaporator, condenser, and ambient temperatures of SAR when using composite adsorbents SGC2 of $90 \mathrm{wt} \%$ silica gel powder and 10wt $\%$ activated carbon powder, with water as a refrigerant on 21 Sep. 2021, is illustrated in Figure 4. The maximum solar radiation intensity of $1091 \mathrm{~W} / \mathrm{m}^{2}$ is available at noontime. Thereafter the amount of available solar radiation intensity decreases till the end of the test. The adsorption bed temperature reached its maximum value of $126^{\circ} \mathrm{C}$ at $2: 00$ p.m then it is reduced gradually, due to water desorption from the heated adsorption bed. While the evaporator temperature reached its lowest value of $3.2{ }^{\circ} \mathrm{C}$ at the end of the test at 6:00 a.m due to water adsorption in the cooled adsorption bed. Regarding the ambient and condenser temperatures, both profile trends are nearly the same with condenser temperature values higher than that of ambient values, due to the extra heat in the desorbed water refrigerant in the condenser. Despite SGC2 gave a higher adsorption bed temperature compared with SGC1, SGC2 produced a lower evaporator temperature due to the delay in desorption and adsorption of water in SGC2. Therefore, SGC1 conducted better performance compared with using SGC2. This may be attributed to the extra quantity of activated carbon on the composite adsorbent SGC2. 


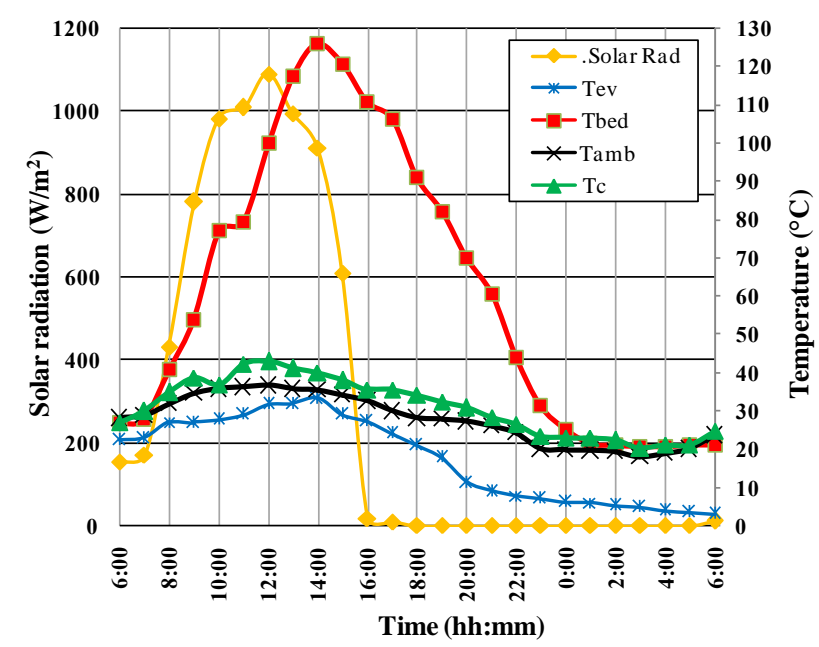

Fig.4 SAR with SGC2 temperature and solar intensity profiles on 21 Sep. 2021.

As can be shown in Fig. 5, the average COP of proposed SAR when using SGC1 and SGC2 with a comparison of Liu et. al. [13]. As illustrated in the mentioned figure, using SGC1 gives a higher COP value of 0.174 than that for SGC2 of 0.131 due to the ability of SGC1 to adsorb and desorb more water refrigerant, while COP of using pure silica gel as an adsorbent in Liu et. al. [13] system gives the highest value of 0.256 .

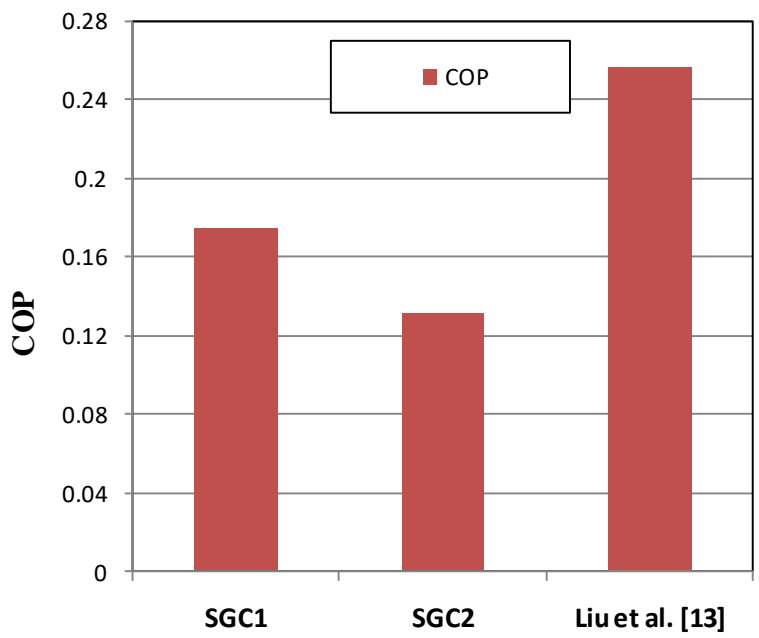

Fig.5 Comparison of the daily average COP for the proposed SAR with Liu et al. [13].

Figure 6 presents a comparison between the values of SCP when using SGC1, SGC2 and pure silica gel of Liu et. al. [13]. The illustrated data showed that the proposed system with SGC1 produced the highest value of SCP of 19.89 $\mathrm{W} / \mathrm{kg}_{\text {ads }}$ among the compared values of $13.21 \mathrm{~W} / \mathrm{kg}_{\text {ads }}$ for
SGC2 and of $8.13 \mathrm{~W} / \mathrm{kg}_{\text {ads }}$ for pure silica gel of Liu et. al. [13].

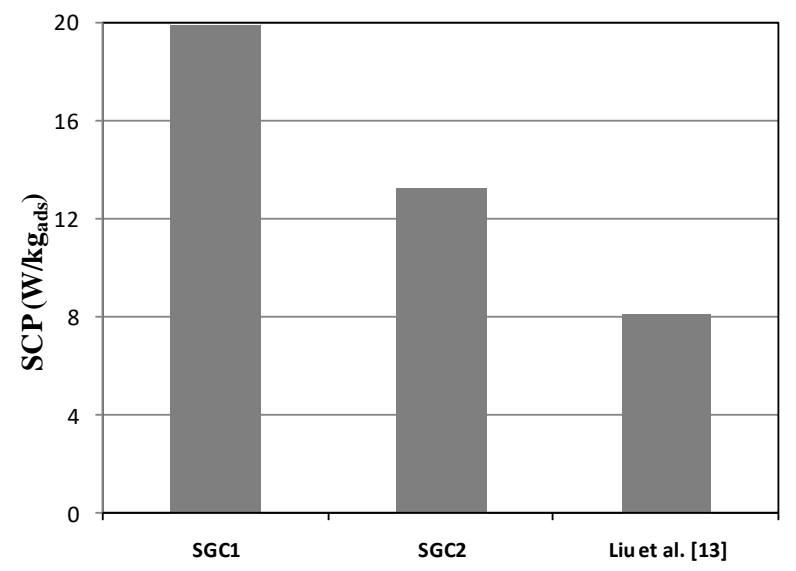

Fig.6 Comparison of the SCP for the proposed SAR with Liu et al. [13].

\section{Conclusion}

The main purpose of this work is to develop a solar adsorption refrigeration apparatus for cold production, and accommodate with the hot climate and arid regions in Upper Egypt. The effect of weather conditions of Qena City on the performance of the tested solar adsorption refrigerator equipped with two new composite adsorbents of SGC1, and SGC2 with water refrigerant is carried out. The reported outcomes can be summarized as:

$>$ SGC1 gives better temperatures performance than SGC2 under the same conditions.

$>\quad$ The average value of COP under using SGC1 reached about 0.174 higher than 0.131 of SGC2.

$>$ Comparing SCP under using SGC1 and SGC2 with pure silica gel in open literature indicated better values especially for SGC1.

$>$ Using SGC1 is preferred as an adsorbent for SAR under harsh climates.

$>$ The proposed new composite adsorbents are beneficial for storing vegetables and fruit in remote and rural areas where electrical power sources are insufficient or unavailable. 


\section{Authors' Contributions:}

Ahmed Nagah Shmroukh (Conceptualization, Resources, Data collection, Writing - original draft, Data curation, Formal analysis, Investigation, Methodology, Writing review \& editing).

Essam Hares (Formal analysis, Supporting, Materials acquisition, Writing - review \& editing).

Osama Hamdy (Formal analysis, Supporting, Software, Validation, Writing - review \& editing).

Mostafa Abouelsoud (Data collection, Formal analysis, Conceptualization, Methodology, Writing - review \& editing).

\section{References}

[1] Massaud Mostafa, M Ezzeldien, M Attalla, Nouby M Ghazaly, ZA Alrowaili, MF Hasaneen, Ahmed N Shmroukh. Comparison of different adsorption pairs based on zeotropic and azeotropic mixture refrigerants for solar adsorption ice maker. Environmental Science and Pollution Research, vol. 28 (2021), 41479-41491.

[2] Mohamed M. Younes, Ibrahim I. El-Sharkawy, A.E. Kabeel, Kutub Uddin, Takahiko Miyazaki, Bidyut Baran Saha. Characterization of silica gel-based composites for adsorption cooling applications. International Journal of Refrigeration. vol 118 (2020), pp 345-353.

[3] Ahmed N. Shmroukh, Ahmed Hamza H. Ali, Ali K. Abel-Rahman. Experimental Study on Adsorption Capacity of Activated Carbon Pairs with Different Refrigerants. International Journal of Chemical, Nuclear, Materials and Metallurgical Engineering, vol 7 (2013), pp 461-467.

[4] M.M. Younes, I.I. El-Sharkawy, A.E. Kabeel, B.B. Sa ha. A review on adsorben- t-adsorbate pairs for cooling applications. Applied Thermal Engineering. vol 114 (2017), pp 394-414.

[5] K.R. Ullah, R. Saidur, H.W. Ping, R.K. Akikur, N.H. Sh uvo. A review of so- lar thermal refrigeration and cooling methods. Renewable and Sustainable Energy Reviews. vol 24 (2013), pp 499-513.

[6] H.T. Chua, K.C. Ng, A. Chakraborty, N.M. Oo, M.A. Ot hman. Adsorption characteristics of silica Gel + water systems. Journal of Chemical Engineering Data, vol 47 (2002), pp 1177-1181.

[7] Q.W. Pan, R.Z. Wang, L.W. Wang, D. Liu. Design and experimental study of a silica gel-water adsorption chiller with modular adsorbers. International Journal of Refrigeration, vol 67 (2016), pp 336-344.

[8] K.C. Ng, H.T. Chua, C.Y. Chung, C.H. Loke, T. Kashiw agi, A. Akisawa, B.B. Saha. Experimental investigation of the silica gel-water adsorption isotherm characteristics. Applied Thermal Engineering, vol 21 (2001), pp 1631-1642.

[9] I.I. El-Sharkawy, H. AbdelMeguid, B.B. Saha. Potential application of solar powered adsorption cooling systems in the Middle East. Applied Energy, vol 126 (2014), pp 235-245.

[10] L.Q. Zhu, Z.W. Gong, B.X. Ou, C.L. Wu. Performance analysis of four types of adsorbent beds in a double-adsorber adsorption refrigerator. Procedia Engineering, vol 121 (2015), pp 129-137.

[11] Z. He, Y. Bai, H. Huang, J. Li, Huhetaoli, N. Kobayashi, Y. Osaka, L. Deng. Study on the performance of compact adsorption chiller with vapor valves. Applied Thermal Engineering, vol 126 (2017), pp 37-42.

[12] P.J. Vodianitskaia, J.J. Soares, H. Melo, J.M. Gurgel. Experimental chiller with silica gel: adsorption kinetics analysis and performance evaluation. Energy Conversion and Management, vol 132 (2017), pp. 172-179.

[13] Y.M. Liu, Z.X. Yuan, X. Wen, C.X. Du. Evaluation on performance of solar adsorption cooling of silica gel and SAPO-34 zeolite. Applied Thermal Engineering, vol 182 (2021), 116019.

[14] Ahmed N. Shmroukh, Shinichi Ookawara. Evaluation of transparent acrylic stepped solar still equipped with internal and external reflectors and copper fins. Thermal Science and Engineering Progress, vol 18 (2020), 100518.

[15] Ahmed N. Shmroukh, Shinichi Ookawara. Stepped Solar Stills' Development and Improvement for Seawater Desalination. SVU-International Journal of Engineering Sciences and Applications, vol 2 (2021), pp 26-36..

[16] Himsar Ambarita, Hideki Kawai. Experimental study on solar-powered adsorption refrigeration cycle with activated alumina and activated carbon as adsorbent. Case Studies in Thermal Engineering, vol 7 (2016), pp 36-46.

[17] Ahmed N. Shmroukh, Ahmed Hamza H. Ali, Ali K. Abel-Rahman, S. Ookwara. NVESTIGATION OF HEAT AND MASS TRANSFER IN ACTIVATED CARBON GRANULES/R-134A ADSORBENT PAIR FOR COMPACT ADSORPTION CHILLER. International Journal of Research in Engineering and Technology, vol 4 (2015), pp 857-865.

[18] Ahmed N. Shmroukh. Thermal regulation of photovoltaic panel installed in Upper Egyptian conditions in Qena. Thermal Science and Engineering Progress, vol. 14 (2019), 100438.

[19] Shahab Edin Hamrahi, Koorosh Goudarzi, Mahmood Yaghoubi. Experimental study of the performance of a continues solar adsorption chiller using Nano-activated carbon/methanol as working pair. Solar Energy, vol 173 (2018), pp 920-927.

[20] Rashed D. Aldughpassi Ahmed N. Shmroukh, Gamal Tag Abdel-Jaber. Solar Seawater Desalination Still With Seawater Preheater Using Efficient Heat Transfer Oil: Numerical Investigation and Data Verification. International Journal of Energy and Environmental Engineering, vol 13 (2019), pp 153-156.

[21] A. N. Shmroukh, I. M. S. Taha, A. M. Abdel-Ghany, M. Attalla. DESIGN AND EVALUATION OF DIFFERENT DEVICES FOR MEASURING AIR DRY-BULB TEMPERATURE IN A FOGGY ENVIRONMENT. Journal of Engineering Sciences, vol 40 (2012), pp 419-432.

[22] Ahmed N Shmroukh, Ahmed A Serageldin, Abdalla Abdal-hay, Ahmed Elreedy, Ali Radwan. Application of new series connection scheme of vortex tubes in seawater desalination unit using new vortex generators. SN Applied Sciences, vol 3 (2021), pp 1-13. 